\title{
PERENCANAAN PEMANFAATAN MARINE FUEL OIL (MFO) SEBAGAI BAHAN BAKAR ENGINE DIESEL MaK
}

\author{
Hendra Poeswanto ${ }^{1)}$ Ahmad Yani ${ }^{2)}$ \\ Jurusan Teknik Mesin Fakultas Teknik Universitas Trunajaya Bontang. ${ }^{1,2)}$ \\ Jl.Taekwondo RT.9 No. 55 Telp./Fax. (0548) 3035920 Bontang-Kaltim 75311 \\ Email: hendrapoeswanto@gmail.com
}

\begin{abstract}
Abstrak
PT. PLN (Persero) Area Bontang tengah berupaya melakukan penggantian jenis bahan bakar pada engine diesel merk MaK yang semula menggunakan High Speed Diesel (HSD) menjadi Marine Fuel Oil (MFO). Tujuan penelitian ini untuk mengetahui proses treatment bahan bakar MFO untuk menurunkan viscositas dan penyeragaman ukuran partikel bahan bakar pada engine diesel merk MaK dan mengetahui perbandingan biaya penghematan dan evisiensi pemakaian bahan bakar HSD dengan bahan bakar MFO. Metode yang digunakan analisa perpindaahan panas pada oil heater dan viskositas bahan bakar yang digunakan untuk menentukan proses treatment bahan bakar MFO. Dari hasil perencanaan, proses treatment menggunakan oli heater dimana proses pemanasan oli dengan memanfaatkan panas dari gas buang hasil pembakaran. Dengan penggunaan bahan bakar MFO dapat menghemat biaya konsumsi bahan bakar sebesar Rp. 21.827.520,- per harinya.
\end{abstract}

Kata Kunci : Engine diesel, HSD, MFO, Treatment, Oil heater

\section{PENDAHULUAN}

Energi listrik merupakan salah satu faktor penunjang yang sangat penting bagi perkembangan secara menyeluruh suatu daerah. Di Kota Bontang, dengan semakin meningkatnya kegiatan industri dan jumlah penduduknya, maka kebutuhan energi listrik juga mengalami peningkatan.

PT. PLN (Persero) Area Bontang adalah salah satu perusahaan listrik yang ada di Kota Bontang. PT. PLN (Persero) Area Bontang menggunakan engine diesel sebagai penggerak mula (prime mover). Prime mover merupakan peralatan yang mempunyai fungsi menghasilkan energi mekanis yang diperlukan untuk memutar rotor generator. Dimana salah satu engine diesel yang digunakan adalah MaK Maschinenbau Gmbh type 8M 453 B yang dapat memproduksi listrik $2544 \mathrm{~kW}$ dengan menggunakan bahan bakar High Speed Diesel (HSD) atau disebut dengan minyak solar.

Dengan adanya kenaikan harga bahan bakar maka proses produksi listrik PT. PLN
(Persero) Area Bontang tengah berupaya melakukan penggantian jenis bahan bakar pada engine diesel merk MaK yang semula menggunakan High Speed Diesel (HSD) menjadi Marine Fuel Oil (MFO).

Bahan bakar Marine Fuel Oil (MFO) adalah Minyak Bakar bukan merupakan produk hasil destilasi, tapi hasil dari jenis residu yang berwarna hitam. Minyak jenis ini memiliki tingkat kekentalan yang tinggi dibandingkan minyak diesel. Sehingga pemanfaatan MFO sebagai bahan bakar tidak dapat diaplikasikan secara langsung, akan tetapi harus melalui proses treatment yang bertujuan untuk menurunkan viscositas atau kekentalan dan penyeragaman ukuran partikel bahan bakar (untuk menghindari sumbatan pada nozzle).

Berdasarkan penjelasan yang ada diatas, maka perlunya dilakukan perencanaan ini guna memperoleh hasil kerja maksimal pada engine diesel merk MaK berbahan bakar MFO. 
Berdasarkan latar belakang yang diuraikan diatas maka dapat dirumuskan permasalahan sebagai berikut :

1. Bagaimanakah proses treatment bahan bakar MFO untuk menurunkan viscositas atau kekentalan dan penyeragaman ukuran partikel bahan bakar pada engine diesel merk MaK?

2. Berapakah perbandingan biaya penghematan dan evisiensi pemakaian bahan bakar HSD dengan bahan bakar MFO sebagai bahan bakar utama engine diesel merk MaK?

\section{TINJAUAN PUSTAKA}

Pembangkit Listrik Tenaga Diesel (PLTD) ialah Pembangkit listrik yang menggunakan mesin diesel sebagai penggerak mula (prime mover). Prime mover merupakan peralatan yang mempunyai fungsi menghasilkan energi mekanis yang diperlukan untuk memutar rotor generator. Mesin diesel sebagai penggerak mula PLTD berfungsi menghasilkan tenaga mekanis yang dipergunakan untuk memutar rotor generator.

\section{Prinsip Kerja PLTD}

1. Di dalam mesin diesel terjadi penyalaan sendiri, karena proses kerjanya berdasarkan udara murni yang dimanfaatkan di dalam silinder pada tekanan yang tinggi (35 - 50 atm), sehingga temperatur di dalam silinder naik. Dan pada saat itu bahan bakar disemprotkan dalam silinder yang bertemperatur dan bertekanan tinggi melebihi titik nyala bahan bakar sehingga akan menyala secara otomatis yang menimbulkan ledakan bahan bakar.

2. Ledakan pada ruang bakar tersebut menggerak piston yang kemudian pada poros engkol dirubah menjadi energi mekanis. Tekanan gas hasil pembakaran bahan bakar dan udara akan mendorong piston yang dihubungkan dengan poros engkol menggunakan batang piston, sehingga piston dapat bergerak bolakbalik.

Gerak bolak-balik piston akan diubah menjadi gerak rotasi oleh poros engkol. Dan sebaliknya gerak rotasi poros engkol juga diubah menjadi gerak bolak-balik piston pada langkah kompresi.

3. Poros engkol mesin diesel digunakan untuk menggerakan poros rotor generator. Pada generator energi mekanis ini dirubah menjadi energi listrik sehingga terjadi gaya gerak listrik.

4. Tegangan yang dihasilkan generator dinaikan tegangannya menggunakan trafo step up agar energi listrik yang dihasilkan sampai ke beban.

5. Menggunakan saluran transmisi energi listrik disalurkan ke beban. Di sisi beban tegangan listrik diturunkan kembali menggunakan trafo step down.

\section{Sistem Bahan Bakar}

Bahan bakar minyak diperlukan sebagai sumber energi bagi mesin diesel. Untuk penyalurannya sampai pada ruang bakar dengan suatu kondisi tertentu diperlukan suatu sistem bahan bakar.

Fungsi system bahan bakar :

1. Mengatomkan atau mengabutkan bahan bakar agar mudah bercampur merata dengan udara sehingga mudah terbakar.

2. Mengatur jumlah bahan bakar yang sama pada setiap pemasukan disetiap silinder pada setiap kebutuhan sehingga tenaga ( power ) setiap silinder adalah sama.

3. Mengatur saat mulai penyemprotan dan lamanya penyemprotan. 


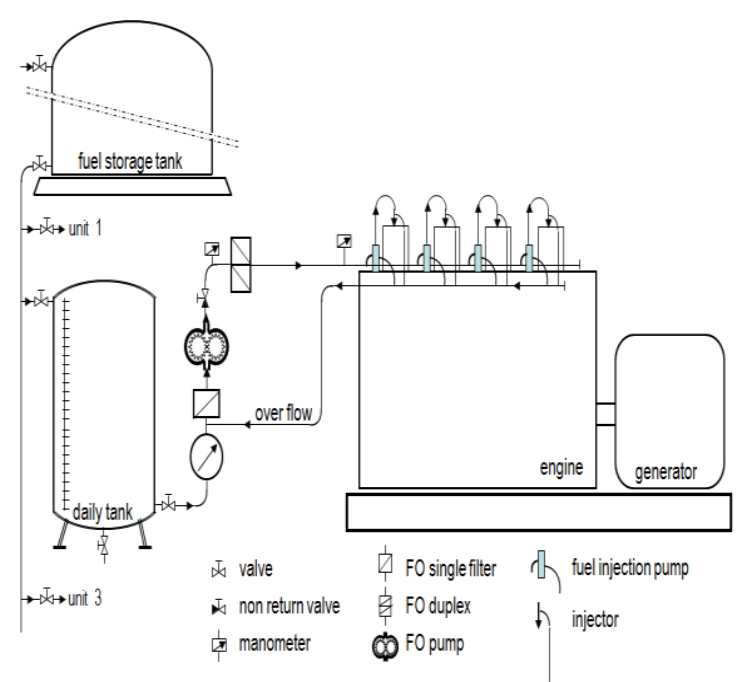

Gambar 1. Prinsip aliran sistem bahan bakar

\section{Jenis Bahan Bakar}

Bahan bakar adalah zat yang dapat dibakar dengan cepat bersama udara (oksigen) dan akan menghasilkan panas. Proses terjadinya api ( pembakaran ) dikenal dengan nama segitiga api, yaitu unsur bahan bakar, unsur udara (oksigen) dan energi panas. Bila ketiga unsur ini bertemu dan mencapai kosentrasi yang tepat, maka akan terjadi proses pembakaran.

Jenis-jenis bahan bakar yang digunakan pada engine MaK Maschinenbau Gmbh type 8M 453 B di PT. PLN (Persero) Area Bontang adalah High Speed Diesel (HSD). Dengan adanya kenaikan haraga bahan bakar maka engine MaK berencana menggunakan bahan bakar Marine Fuel Oil (MFO) sebagai bahan bakar.

\section{High Speed Diesel (HSD)}

$$
\text { High Speed Diesel (HSD) }
$$

merupakan jenis solar yang memiliki angka performa cetane number 45 , bahan bakar ini umumnya digunakan untuk mesin diesel yang umum dipakai dengan sistem injeksi pompa mekanik (injection pump) dan electronic injection.

HSD mengalir dari fuel storage tank menuju daily tank (tangki harian) dengan menggunakan booster pump. Namun sebelum masuk menuju booster pump terlebih dahulu disaring oleh single filter melewati flowmeter.

Bahan bakar HSD dimasukkan ke mesin dengan fuel injection pump dan injektor. Bahan bakar HSD di pompakan menggunakan injection pump dengan tekanan tinggi ke injektor, kemudian injektor mengubah bahan bakar menjadi kabut ke silinder sesuai dengan urutan waktu penyalaan atau pembakaran (firing order).

\section{Marine Fule Oil (MFO)}

Marine Fuel Oil (MFO) adalah produk penyulingan minyak bumi, dimana dihasilkan setelah residu dan sebelum aspal. Yaitu minyak bakar yang bukan merupakan produk hasil destilasi tetapi hasil dari jenis residu yang berwarna hitam. Minyak jenis ini memiliki tingkat kekentalan yang tinggi dibandingkan minyak diesel. Pemakaian minyak bakar ini umumnya untuk pembakaran langsung pada industri besar dan digunakan sebagai bahan bakar untuk steam power station. Selain itu bahan bakar MFO juga dipakai sebagian besar untuk bahan bakar mesin kapal. Dilihat dari segi ekonomi penggunaan minyak bakar ini dinilai lebih murah.

\section{Alur sistem treatmen MFO}

\section{Storage Tank}

Tempat penimbunan cadangan bahan bakar, pengendapan lumpur, kotoran padat dan kandungan air jenuh. Dimana temperatur MFO dijaga $60-80{ }^{\circ} \mathrm{C}$ untuk mempermudah proses pemompaan.

\section{Settling Tank}

Tempat penyimpanan sementara MFO siap disaring dan menurunkan kandungan air lebih. Dimana temperatur pemanas dijaga $90-100{ }^{\circ} \mathrm{C}$ untuk menjaga panas MFO pada $80-90{ }^{\circ} \mathrm{C}$ agar tidak terjadi penggumpalan partikel MFO menjadi aspal.

\section{Sparator}

Tempat pemisahan air dan partikel MFO berdasar berat jenis. Dimana pemanas 
MFO pada $80-100{ }^{\circ} \mathrm{C}$ (Alarm sparator akan bekerja pada temperatur $>100{ }^{\circ} \mathrm{C}$ ).

4. Daily Tank

Penyimpan sementara MFO siap dipergunakan untuk mesin diesel. Dimana temperatur MFO dijaga pada $90{ }^{\circ} \mathrm{C}$.

5. Booster Module

Menetapkan viscositas dan temperatur MFO sebelum masuk sistem bahan bakar mesin diesel.

\section{Change Over}

Pengubahan saluran bahan bakar menuju mesin diesel dengan pilihan Solar atau HSD dan MFO (untuk start up, mesin diesel memerlukan bahan bakar Solar atau HSD)

\section{Over Flow Tank}

Penampungan bahan bakar berlebih dari mesin diesel

\section{Sludge Tank}

Penampungan sludge atau MFO dengan partikel besar dan air dari sparator

\section{Perpindahan Panas Pada Proses Treatmen}

Proses treatment MFO adalah proses penurunan viscositas dan proses penyeragamaan ukuran partikel bahan bakar ( untuk menghindari sumbatan pada nozzle ). Cara perpindahan panas pada proses teratment MFO yaitu secara konduksi dan konveksi.

Konduksi adalah proses perpindahan panas jika panas mengalir dari tempat yang suhunya tinggi ke tempat yang suhunya lebih rendah, dengan media penghantar panas tetap.

Perpindahan panas konduksi ini terjadi pada system perpipaan pada aliran treatmen bahan bakar MFO. Perpindahan secara konduksi dapat dilihat pada gambar 2 . dimana perpindahan yang diakibatkan perbedaan suhu.

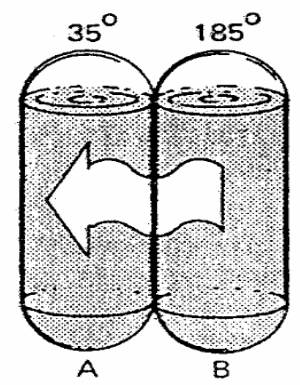

\section{Gambar 2. Perpindahan panas secara konduksi}

Konveksi adalah perpindahan panas yang terjadi antara permukaan padat dengan fluida yang mengalir di sekitar, dengan menggunakan media penghantar beruap fluida (cairan atau gas ).

Perpindahan panas konveksi ini terjadi pada system perpindahan panas pada tangki bahan bakar MFO. Perpindahan secara konveksi dapat dilihat pada gambar

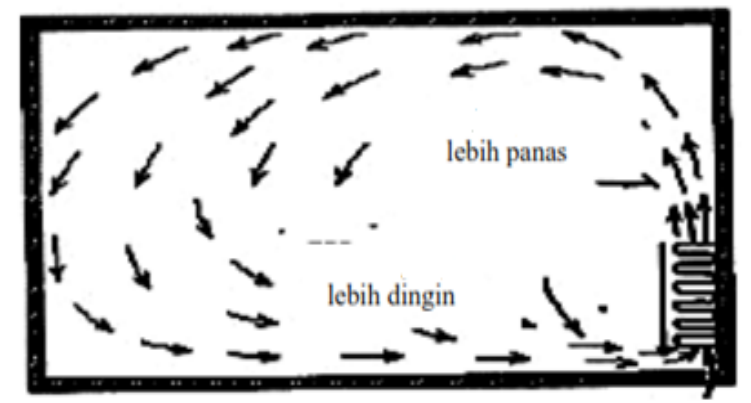

Gambar 3. Perpindahan panas secara konveksi

\section{Konsumsi Bahan Bakar}

Besar pemakaian bahan bakar spesific (SFC) ditentukan dalam $\mathrm{g} / \mathrm{PSh}$ atau $\mathrm{g} / \mathrm{kWh}$ dan umum digunakan dari pada $\mathrm{kg} / \mathrm{kWh}$. Besar nilai SFC adalah kebalikan dari pada

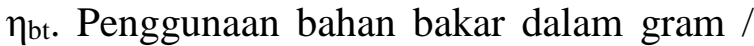
jam Ne dapat ditentukan dengan persamaan sebagai berikut :

$$
S F C=\frac{m_{f}}{P}(k g / k W h)
$$

Dimana :

SFC = konsumsi bahan bakar sfesifik $(\mathrm{kg} / \mathrm{kWh})$

$\mathrm{P} \quad=$ daya mesin $(\mathrm{kW})$

$m_{f}=$ penggunaan bahan bakar per jam pada kondisi tertentu

METODE PENELITIAN 


\section{Waktu dan Tempat Penelitian}

Waktu penelitian ini dilakukan mulai dari bulan Mei 2014 sampai dengan Desember 2014. Tempat dilaksanakannya penelitian ini bertempatan PT. PLN (Persero) Area Bontang.

\section{Jenis dan Sumber Data}

Berdasarkan sumbernya, data penelitian ini dapat dikelompokan dalam dua jenis yaitu data primer dan data sekunder.

Data primer adalah data yang diperoleh atau dikumpulkan secara langsung dari sumber data dalam penelitian. Dimana data primer yang diperoleh dari penelitian ini adalah :

\section{Mesin Induk}

Merk

: MaK Maschinenbau Gmbh

Tipe

: $8 \mathrm{M} 453 \mathrm{~B}$

Daya

: $2544 \mathrm{~kW}$

Jlh. Silinder $: 8$

Diameter : $320 \mathrm{~mm}$

Panjang Lang. : $420 \mathrm{~mm}$

Putaran Mesin : $600 \mathrm{rpm}$

SFC $\quad: 0.275$ liter $/ \mathrm{kWh}$

Data sekunder adalah data yang diperoleh atau dikumpulkan dari berbagai sumber data yang telah ada. Pada penelitian ini data sekunder yang diperoleh adalah karasteristik bahan bakar HSD dan MFO.

\section{HASIL DAN PEMBAHASAN}

\section{Perhitungan}

1. Volume langkah dan volume ruang bakar

$\mathrm{V}_{1}=\frac{\pi}{4} D^{2} L$

$\mathrm{V}_{1}=\frac{\pi}{4} \times 0,32^{2} \times 0,42$

$\mathrm{V}_{1}=33,78$ liter

$\mathrm{V}_{2}=\frac{\mathrm{V}_{1}}{r}$

$r$ adalah perbandingan kompresi

$=(18)$

$\mathrm{V}_{2}=\frac{\mathrm{V}_{1}}{r}$
$\mathrm{V}_{2}=\frac{33,78}{18}$

$\mathrm{V}_{2}=1,877$ liter $=1877 \mathrm{cc}$

2. Temperatur tiap proses

$\mathrm{T}_{2}=700^{\circ} \mathrm{C}=973.15 \mathrm{~K}$

$\mathrm{T}_{1}=\mathrm{T}_{2}\left(\frac{\mathrm{V}_{2}}{\mathrm{~V}_{1}}\right)^{k-1} \quad \mathrm{k}=1.4$

$\mathrm{T}_{1}=973.15\left(\frac{1}{18}\right)^{1,4-1}$

$\mathrm{T}_{1}=306.25 \mathrm{~K}$

$\mathrm{T}_{3}=\mathrm{T}_{2}\left(\frac{\mathrm{V}_{3}}{\mathrm{~V}_{2}}\right)$

Dimana : $\frac{\mathrm{V}_{3}}{\mathrm{~V}_{2}}=r_{c}$ adalah rasio cutoff, $r_{c}=2$

$\mathrm{T}_{3}=\mathrm{T}_{2} \times r_{c}$

$\mathrm{T}_{3}=973.15 \times 2$

$\mathrm{T}_{3}=1946.3 \mathrm{~K}$

$\mathrm{T}_{4}=\mathrm{T}_{3}\left(\frac{\mathrm{V}_{3}}{\mathrm{~V}_{4}}\right)^{k-1}=\mathrm{T}_{3}\left(\frac{\mathrm{r}_{c}}{r}\right)^{k-1}$

$\mathrm{T}_{4}=1946.3\left(\frac{2}{18}\right)^{1.4-1}$

$\mathrm{T}_{4}=808.19 \mathrm{~K}$

Data yang diperoleh :

$\mathrm{T}_{1}=306.25 \mathrm{~K}=33.1^{\circ} \mathrm{C}$

$\mathrm{T}_{2}=973.15 \mathrm{~K}=700^{\circ} \mathrm{C}$

$\mathrm{T}_{3}=1946.3 \mathrm{~K}=1673.15^{\circ} \mathrm{C}$

$\mathrm{T}_{4}=808.19 \mathrm{~K}=535.04{ }^{\circ} \mathrm{C}$

3. Kalor Masuk dan Kalor Keluar

$c_{v}=0.7175 \mathrm{~kJ} / \mathrm{kg}$

$c_{p}=1.0045 \mathrm{~kJ} / \mathrm{kg}$

$q_{\text {in }}=c_{p}\left(T_{3}-T_{2}\right)$

$q_{\text {in }}=1.004 \times(1946.3-700)$

$q_{\text {in }}=1251.285 \mathrm{~kJ} / \mathrm{kg}$

$q_{\text {out }}=c_{v}\left(T_{4}-T_{1}\right)$

$q_{\text {out }}=0.7175 \times(808.19-306.25)$

$q_{\text {out }}=360.142 \mathrm{~kJ} / \mathrm{kg}$

Jadi, kalor masuk $1251.285 \mathrm{~kJ} / \mathrm{kg}$ dan kalor keluar $306.142 \mathrm{~kJ} / \mathrm{kg}$

\section{Proses Teratment Bahan Bakar MFO}

Dalam perencanaan ini proses teratment bahan bakar MFO untuk menurunkan viscositas dari bahan bakar 
MFO menggunakan Oil Heater (pembangkit panas dengan menggunakan oli sebagai media pemanas). Dimana proses pemanasan oli dengan memanfaatkan panas dari sisa hasil pembakaran mesin atau gas buang.

Temperatur gas buang yang dibutuhkan untuk memanaskan oil heater sekitar $300{ }^{\circ} \mathrm{C}$. Dari data hasil perhitungan didapat temperatur gas buang adalah 535.04 ${ }^{\circ} \mathrm{C}$. Sehingga dalam hal ini pemanfaatan temperatur gas buang dapat diaplikasikan sebagai pemanas oil heater.

\section{Proses Pemanasan Oli}

Proses pemanasan oli ini dengan menggunakan pemanfaatan panas dari sisa hasil pembakaran mesin atau gas buang. Oli yang ada pada storage tank akan dipompa untuk bersirkulasi menuju thermal oil. Dimana gas buang dari hasil pembakaran akan ditransfer menuju thermal tank untuk memanaskan oli yang bersirkulasi dalam thermal oil.

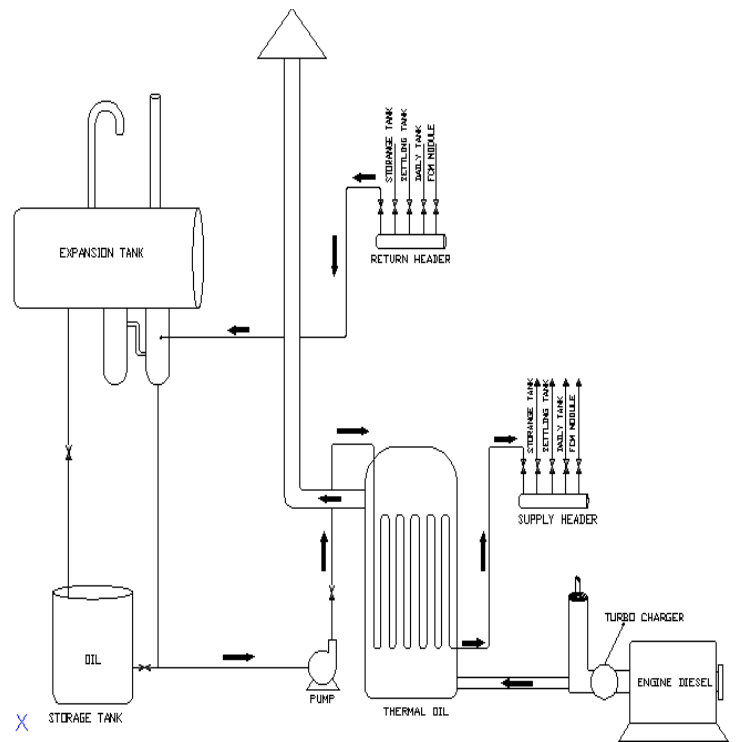

Gambar 4, Proses Pemanasan Oli

Jenis oli yang digunakan adalah Shell Thermal Oil B dengan berat jenis $850 \mathrm{~kg} / \mathrm{m}^{3}$ dan koefisien panas $1.954 \mathrm{kj} / \mathrm{kg} . \mathrm{K}$ pada temperature $40^{\circ} \mathrm{C}$.

Kapasitas panas total yang dibutuhkan pada proses pemanasan oli:

$Q=\mathrm{m} x C_{p} x\left(T_{M 2}-T_{M 1}\right)$

Dimana:

$\mathrm{m} \quad=$ Massa Oli dalam thermal oil (500 $\mathrm{kg})$
$C p \quad=$ Koefisien panas

$\mathrm{T}_{\mathrm{M} 1}=$ Temperatur Oli dalam tangki ( 40 ${ }^{\circ} \mathrm{C}$ )

$\mathrm{T}_{\mathrm{M} 2}=$ Temperatur Oli yang dibutuhkan ( $150{ }^{\circ} \mathrm{C}$ )

Kapasitas panas

$Q=m \times C_{p} \times\left(T_{M 2}-T_{M 1}\right)$

$Q=500 \times 1.954 \times(423.15-313.15)$

$Q=107470 \mathrm{kj}$

Data yang diperoleh dari mesin, panas yang keluar adalah $306.142 \mathrm{~kJ} / \mathrm{kg}$ sedangkan untuk memanaskan oli sebanyak $500 \mathrm{~kg}$ adalah $107.470 \mathrm{~kg}$. sehingga panas gas buang pada mesin dapat diterima.

\section{Proses Treatmen MFO}

Proses treatmen MFO dengan Oil Heater (pembangkit panas dengan menggunakan oli sebagai media pemanas). Oli panas yang berada pada thermal tank akan ditransfer menuju supply header. Dimana temperatur oli pemanas yang keluar dari thermal tank diatur pada $150{ }^{\circ} \mathrm{C}$. Pada supply header transfer oli panas akan diatur sesuai dengan kebutuhan tiap tangki.

Pada storage tank atau tangki utama oli panas ditransfer pada temperatur $90-105{ }^{\circ} \mathrm{C}$, hal ini berfungsi untuk mempermudah proses dari pemompaan bahan bakar MFO menuju settling tank. Pada settling tank oli panas ditransfer pada temperatur $90-100{ }^{\circ} \mathrm{C}$ agar tidak terjadi penggumpalan partikel $\mathrm{MFO}$ menjadi aspal. Pada daily tank oli panas ditransfer pada temperatur $90-100{ }^{\circ} \mathrm{C}$ untuk menjaga temperatur MFO pada $90{ }^{\circ} \mathrm{C}$. MFO yang ada pada daily tank adalah MFO yang siap dipergunakan untuk bahan bakar pada mesin diesel. 


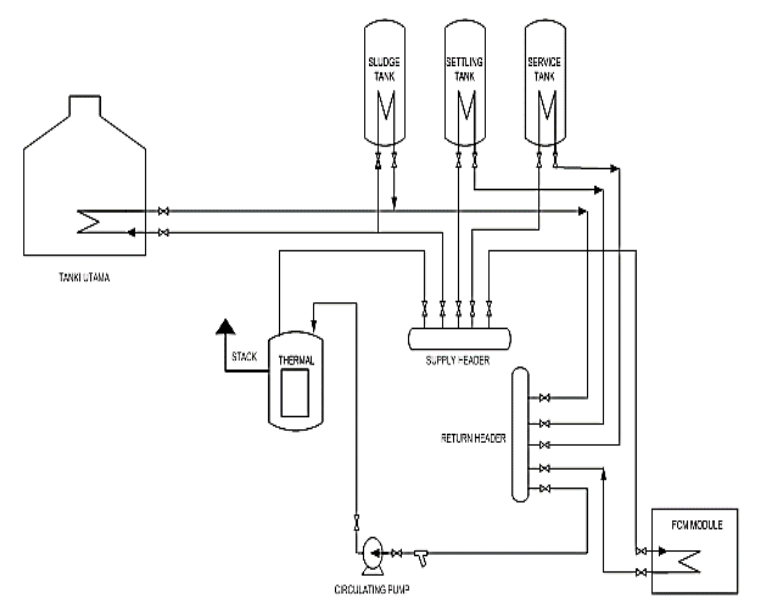

Gambar 5. Proses Treatmen MFO

\section{Aliran Bahan Bakar MFO}

Tanki utama atau storage tank adalah tempat penimbunan cadangan bahan bakar, dimana kapasitas bahan bakar yang dapat disimpan sebanyak 600 Ton bahan bakar MFO.

Bahan bakar MFO yang terdapat pada Storage Tank akan dipompa menuju Settling Tank. Settling tank memiliki kapasitas bahan bakar 20 Ton. Pada settling tank bahan bakar MFO siap disaring dan diturunkan kandungan air yang berlebih.

Bahan bakar yang terdapat pada Settling tank akan dipompa menuju Sparator untuk proses pemisahan kandungan air yang terdapat pada bahan bakar MFO.

Bahan bakar MFO yang siap pakai akan ditampung pada Daily Tank dan limbah dari bahan bakar MFO akan ditampung pada Sludge Tank. Daily tank memiliki kapasitas yang sama dengan settling tank yaitu 20 Ton. Bahan bakar yang siap pakai akan dialirkan menuju booster module atau FCM module untuk menetapkan viscositas dan temperatur MFO sebelum masuk mesin.

Pada saluran masuk mesin terdapat change over sebagai saluran bahan bakar menuju mesin diesel dengan pilihan HSD dan MFO. Change over berperan penting dalam mengatur konsumsi bahan bakar yang akan digunakan. Change over diperlukan karena untuk start up mesin diesel memerlukan bahan bakar HSD.

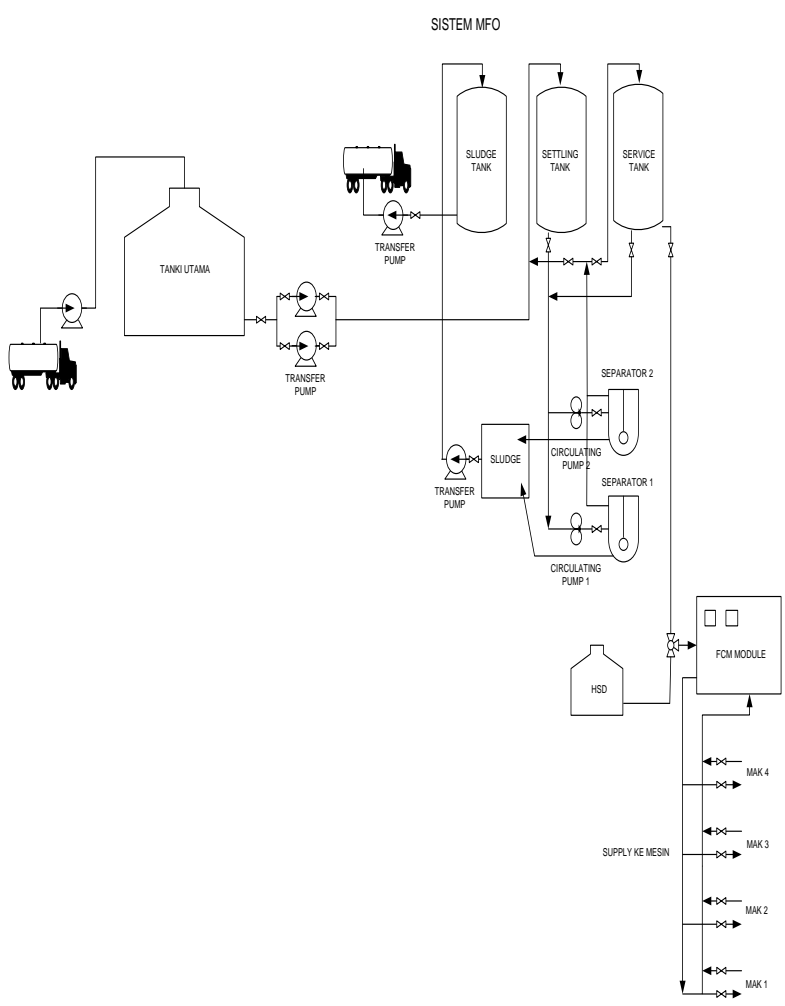

\section{Gambar 6. Aliran Bahan Bakar MFO}

4. Sistem perpipaan pada aliran bahan bakar MFO

Seluruh sistem perpipaan dilengkapi heater yang menempel sepanjang jalur aliran bahan bakar MFO. Hal ini untuk menghindari penggumpalan MFO dalam pipa.

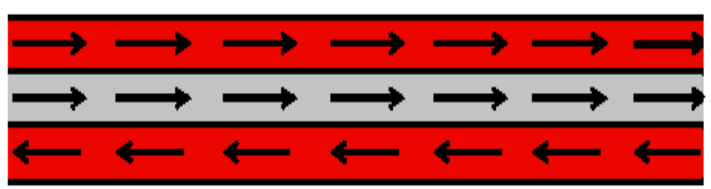

Gambar 7. Aliran bahan bakar MFO dalam pipa

Keterangan :

$\longrightarrow$ : Saluran kembalinya oli panas menuju thermal oil, dimana oli akan dipanaskan kembali.

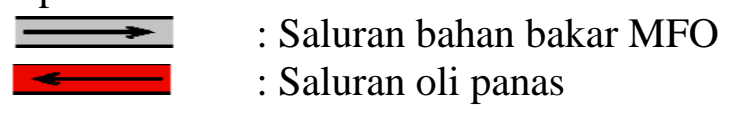

\section{Konsumsi Bahan Bakar}

Berdasarkan data mesin diesel merk MaK Maschinenbau Gmbh type 8M 453 B dimana diperoleh SFC 0.275 liter/kWh maka kebutuhan bahan bakar selama 24 jam adalah sebagai berikut : 


$$
\begin{aligned}
F C & =S F C \times \text { Daya mesin } \\
& =0.275 \times 2544 \\
& =699.6 \text { liter } / \mathrm{jam}
\end{aligned}
$$

Sehingga kebutuhan bahan bakar selama 24 jam adalah :

$$
\begin{aligned}
& F C=699.6 \times 24 \\
& F C=16790.4 \text { liter }
\end{aligned}
$$

\section{Perbandingan Biaya Konsumsi Bahan Bakar HSD dan MFO}

Untuk mengetahui perbandingan biaya konsumsi dapat kita lihat dari harga beli bahan bakar. Dimana harga bahan bakar HSD dan MFO untuk industri sebagai berikut

Harga bahan bakar HSD = Rp. 10.100,- per liter

Harga bahan bakar MFO = Rp. 8.800,- per liter

Perhitungan perbandingan biaya konsumsi bahan bakar selama 24 jam kerja dalam bentuk Rupiah :

$$
\begin{aligned}
\mathrm{HSD} & =16790.4 \times 10100 \\
& =R p .169 .583 .040,- \\
\mathrm{MFO} & =16790.4 \times 8800 \\
& =R p .147 .755 .520,-
\end{aligned}
$$

Sehingga penghematan biaya bahan bakar :

$$
\begin{aligned}
& P_{\text {Biaya }}=H S D-M F O \\
& P_{\text {Biaya }}=R p . 169.583 .040 \\
&-R p .147 .755 .520 \\
& P_{\text {Biaya }}=R p . 21.827 .520,-
\end{aligned}
$$

Dengan data yang diperoleh, maka pengunaan bahan bakar MFO dapat menghemat sebesar Rp. 21.827.520,- per harinya.

\section{KESIMPULAN}

Dari hasil perencanaan pemanfaatan Marine Fuel Oil (MFO) sebagai bahan bakar engine diesel MaK maka didapatkan data sebagai berikut :

1. Proses teratment bahan bakar untuk menurunkan viscositas dari bahan bakar MFO menggunakan Oil Heater. Dimana proses pemanasan oli dengan memanfaatkan panas dari sisa hasil pembakaran mesin atau gas buang.

2. Perbandingan penghematan bahan bakar yang dihasilkan antara bahan bakar HSD dengan bahan bakar MFO. Dimana dengan penggunaan bahan bakar MFO dapat menghemat biaya konsumsi bahan bakar sebesar Rp. 21.827.520,- per harinya.

\section{DAFTAR PUSTAKA}

1. Cengel, Yunus A. 2011. HEAT TRANSFER A Practical Approach. Second Edition.

2. Holman, J. P. 2010. HEAT TRANSFER. Tenth Edition. Mc Graw-Hill

3. L. Streeter Victor, E. Benjamin Wylie. 1999. MEKANIKA FLUIDA. Edisi Delapan Jilid 1. Erlangga. Jakarta.

4. Moran, Michael J., 2011. "Fundamentals of Engineering Thermodynamics", John Wiley \& Sons,Inc,

5. M. White Frank. 1994. Mekanika Fluida. Edisi Kedua Jilid 1. ERLANGGA.Jakarta.

6. Sonntag,Borgnakke, Van Wylen. 2009. FUNDAMENTALS Thermodynamics. Sixth Edition.

7. V. L. Maleev. 1945. INTERNALCOMBUSTION

ENGINES. International student edition. McGraw-Hill Kogakusha. 